\title{
ARF FEE TOO HIGH SAY DENTAL NURSES
}

Just over 4,000 dental care professionals (DCPs) have been removed from the General Dental Council (GDC) register for not paying the annual retention fee (ARF) payment. According to latest figures, 651 other DCPs have specifically asked to be removed for reasons including taking a career break or retiring, and the GDC had successfully processed nearly 53,000 P

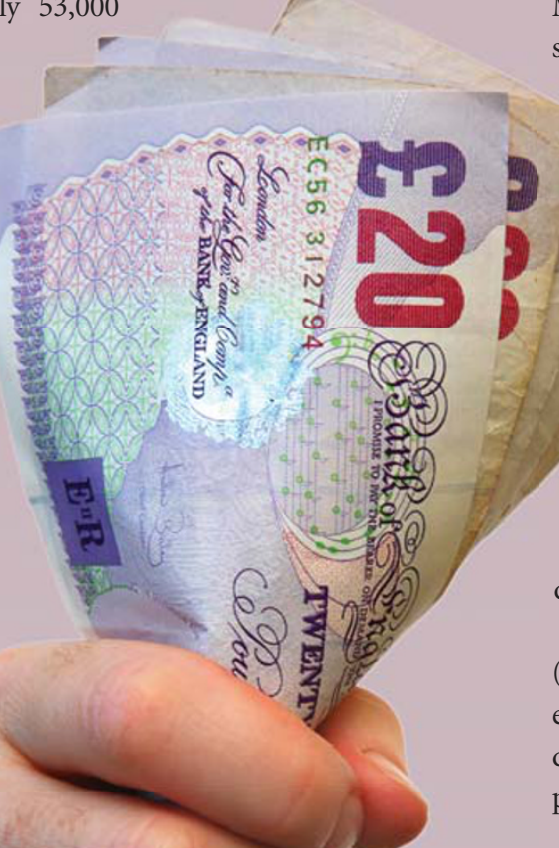

payments at the deadline of 31 July. However,some dental nurses have criticised the GDC for setting the ARF fee at $£ 96$, as dental nurses are charged the same as other DCPs even though they earn much less.

One group of dental nurses felt so strongly over the matter that it has set up its own Facebook group to gather support to try and get the fee lowered for dental nurses. The group's creator, who is also petitioning the Prime Minister over the matter, Xyanthe Lambert said, 'The feedback I have received through my Facebook group and also the growing number of signatories on the online petition [indicate] that it is wholly unfair that the ARF for dental nurses is the same as for technicians and hygienists/ therapists, who have the potential to earn far more. Many dental nurses now feel undervalued having

to pay a disproportionate amount of their salaries for ARF, indemnity insurance and CPD just to be legally allowed to do their job.'

The British Association of Dental Nurses

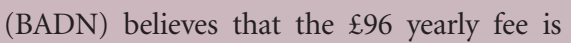
excessive in view of current salary levels for dental nurses, particularly for those who work part time, or at minimum wage levels.

Its Chief Executive, Pam Swain commented, 'There should be a much lower fee for dental nurses and those who work part time should pay a lower fee than their full time colleagues.' She added that fee should also be collected in smaller payments throughout the year, instead of one large payment.
According to the GDC, the ARF fees are reviewed yearly and there was no rise for 2009. A spokesperson said, 'We ran a consultation earlier this year on a draft ARF policy, which was open to all registrants, professional bodies and any other interested parties. The Finance and Human Resources Committee took the view that due to the registration of dental nurses and dental technicians being in its infancy, more time was needed for further work on this issue.'

However BADN President Angie McBain hit back, commenting 'The BADN participated in the GDC's consultation exercise and advised that the fee for dental nurses should be lowered considerably. The response we received from the GDC was that there was insufficient evidence that changes to the fees policy or the current fee structure were necessary at present.'

Now the BADN are conducting an online survey of dental nurse salaries in the UK, in order to present evidence to the GDC about the difficulty some dental nurses are experiencing in paying the fee.

The online survey asks dental nurses about their salary, how they are paid, what additional benefits their employer provides and about their specific domestic circumstances. The BADN will use the results to present a case to the GDC for lowering the fee. Dental nurses are invited to participate in the survey, via a link on the Latest News page of the BADN website at www.badn.org.uk or through a link on the BADN group page on Facebook. The survey will close on 30 September 2009.

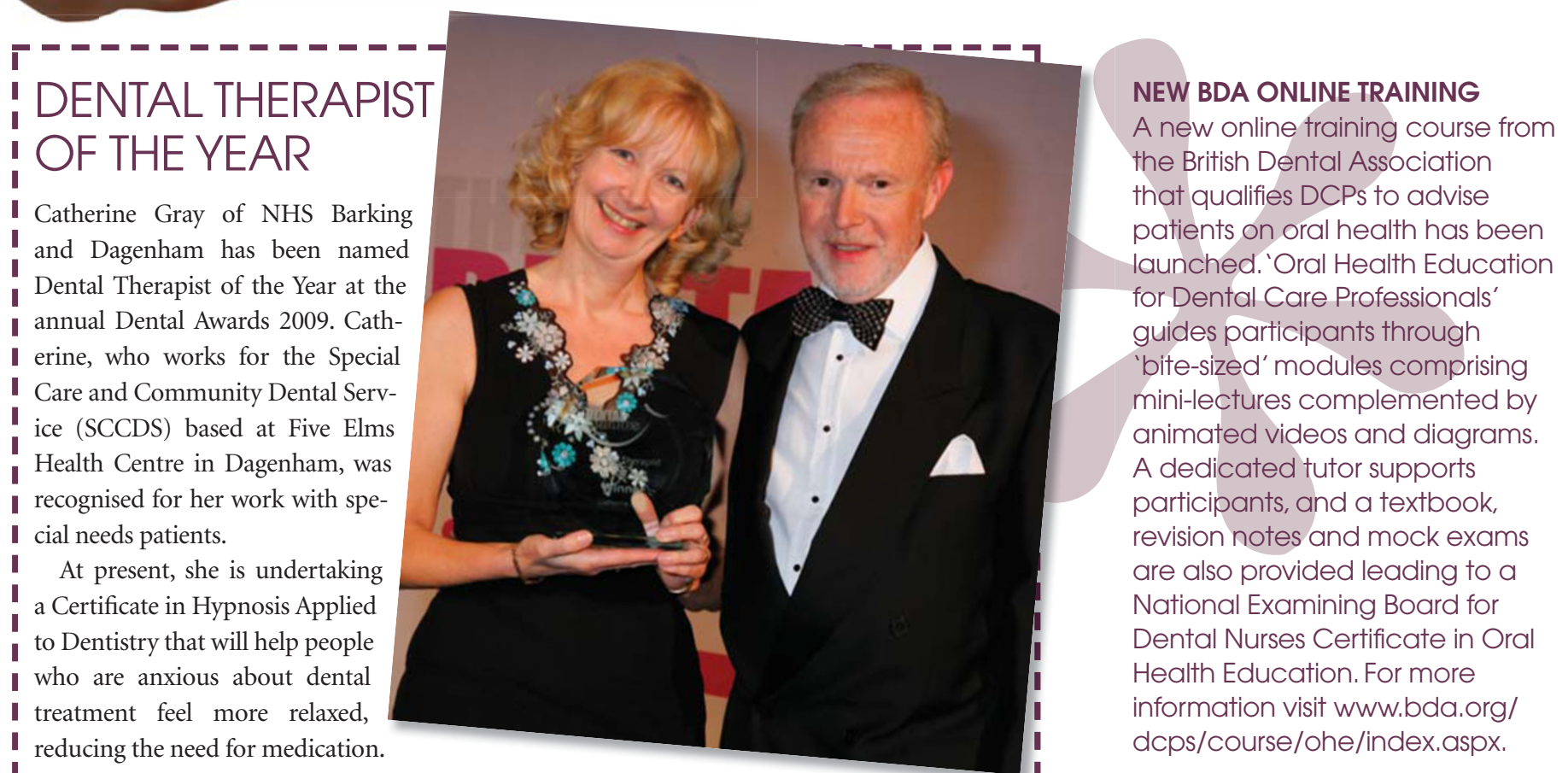

